\title{
Evaluation of Photodynamic Inactivation Efficiency Using Conventional and Decorative Light-Emitting Diode Lamps
}

\author{
Shih-Chen Shi* and Wen-Ke Huang \\ Department of Mechanical Engineering, National Cheng Kung University, \\ No. 1 University Road, Tainan 70101, Taiwan
}

(Received April 21, 2017; accepted August 28, 2017)

Keywords: photodynamic inactivation, photosensitizer, LED, lighting, ROS

We studied the bacterial inactivation effects of conventional and decorative light-emitting diode (LED) lamps. We used erythrosine and toluidine blue $\mathrm{O}$ as photosensitizers, mixed them with bacteria, painted the mixture on nutrient agar (NA), and then irradiated the NA with commercial green, red, and white LED lamps. The experimental results showed a positive photodynamic inactivation effect on Escherichia coli and Staphylococcus aureus reduction in the experiment. Thus, we demonstrated a decrease in the in vitro growth of E. coli and $S$. aureus by using easily available LED lamps. This experiment revealed the possibility of using conventional and decorative lighting for daily bacterial inactivation in the future.

\section{Introduction}

The Paris Agreement signed in the 2015 United Nations Climate Change Conference declared a global consensus on energy saving and carbon dioxide emission reduction. Green technology development is widely discussed. ${ }^{(1-5)}$ To reduce carbon dioxide emissions, adopting lighting products with high energy efficiency is a viable strategy. After all, using resources effectively is essential for the sustainable growth of the global community. In recent years, light-emitting diode (LED) products have been developed rapidly, featuring a high luminous efficacy, an increased luminous power, and the capacity to emit light within a specific range of wavelengths. Consequently, various types of LED products such as conventional and decorative lighting fixtures have become increasingly prevalent in daily life applications. ${ }^{(6,7)}$ In addition to lighting, other LED applications that are harmless to the human body and environment are investigated in this study. For disinfection in home and public spaces, bleach and other disinfectants are commonly applied. Although these substances can effectively reduce bacterial growth, they release pungent odors, injure the human body upon contact, and are harmful to the environment, exhibiting distinct disadvantages. Ultraviolet illumination is another method used to disinfect indoor spaces. However, ultraviolet light accelerates the aging of plastic products, causes notable harm to the eyes, and requires a relatively long time to complete disinfection; therefore, improvements remain to be made regarding this disinfection method.

Photodynamic inactivation (PDI) has attracted considerable research interest and has been successfully used for treating tumors and for sterilization. ${ }^{(8-10)}$ It has also been used for sterilizing wounds to eliminate Escherichia coli or oral pathogens. ${ }^{(11,12)}$ This approach does not require ${ }^{*}$ Corresponding author: e-mail: scshi@mail.ncku.edu.tw http://dx.doi.org/10.18494/SAM.2017.1705 
medication, and hence, does not generate drug resistance. ${ }^{(13-16)}$ Because this sterilization method is effective for treating antibiotic-resistant strains, it has been receiving increasing attention. ${ }^{(17,18)}$ PDI uses a specific-wavelength LED or laser irradiation on a photosensitizer (PS). ${ }^{(19-25)}$ The PS transfers energy to oxygen molecules, producing singlet oxygen $\left({ }^{1} \mathrm{O}_{2}\right)$ or reactive oxygen species (ROS). Superoxide radicals, hydroxyl radicals, lipid-derived radicals, and ROS can oxidize proteins, peroxidize lipids, and damage nucleic acids, resulting in bacterial death. ${ }^{(26-28)}$

Erythrosine (Er) is the US Food and Drug Administration-approved FD\&C Red No. 3. In addition to its use as food coloring, it can also be used as a plaque-disclosing agent, a dye commonly used in dentistry; it can be metabolized by the human body and has been used in the inactivation studies of Streptococcus mutans and Porphyromonas gingivalis. ${ }^{(29-31)}$ Toluidine blue $\mathrm{O}$ (TBO) staining is used in PDI for treating oral lichen planus and in vital staining. ${ }^{(32,33)}$ Therefore, this study assessed the bacterial PDI effect of replacing phenolics, sodium hypochlorite, and alcohols with conventional and decorative LED lamps in daily life disinfection.

In this study, a self-degradable PS was combined with general and decorative LED products that were commonly found in home spaces to assess the PDI effect. In the future, the proposed application is expected to serve as an environmentally friendly method of disinfection to be used in venues such as home and public places, hospitals, and child care centers. In the meantime, the PDI technique has the potential as a bacterial-free safety sensor application in the future.

\section{Materials and Methods}

\subsection{Sample preparation}

The E. coli strain (ATCC 8739) and Staphylococcus aureus strain (ATCC 6538) were provided by the Center for Micro/Nano Science and Technology, Nataurional Cheng Kung University, Taiwan. TBO was procured from Acros, New Jersey, USA, and Er was procured from Sigma, Poole, UK. We added $5000 \mu \mathrm{g}$ of the PS to $9 \mathrm{~mL}$ of phosphate buffered saline (PBS) and vortexed the mixture for $1 \mathrm{~min}$, filtered it through a $0.22-\mu \mathrm{m}$-pore-size sieve, and mixed it with $1 \mathrm{~mL}$ of $E$. coli or an S. aureus aqueous solution $\left(5 \times 10^{8} \mathrm{CFU} / \mathrm{mL}\right)$ for $10 \mathrm{~min}$. A $100 \mu \mathrm{L}$ mixture of PS and bacterial solution was painted on the nutrient agar (NA) through the plating technique and then irradiated with LED lamps for $60 \mathrm{~s}$.

NA was placed in an incubator (721, Hipoint, Taiwan) at $35{ }^{\circ} \mathrm{C}$ for $24 \mathrm{~h}$ after LED irradiation. Residual colony analyses were conducted using $100 \mu \mathrm{L}$ of bacterial/PS aqueous solution added into $9.9 \mathrm{~mL}$ of PBS, vortexed for $10 \mathrm{~s}$, painted on the NA at $35^{\circ} \mathrm{C}$, and stored for $24 \mathrm{~h}$.

\subsection{LED lamps}

The commercial LED lamps used in this experiment were provided by a LED company; the instrument setup is shown in Fig. 1. To prevent the system from overheating, a heatsink was used for the LED light board, and this light board was forcedly cooled with a $12 \mathrm{~V}$ DC cooling fan [Fig. 1(b)] to prevent damage to the LED lamps [Fig. 1(c)]. The power consumption of the LED lamps was set to $25 \mathrm{~W}$. The surface of the NA was continuously irradiated for 5 min at a cumulative temperature that did not exceed $38{ }^{\circ} \mathrm{C}$ [Fig. 1(d)], preventing bacterial death because of the heat generated from the LED lamps.

The decorative LED lamps used for this experiment (sourced from the Everlight Electronic, Taiwan) had two wavelengths - green light $(525 \mathrm{~nm})$ and red light $(630 \mathrm{~nm})$. Each high-efficacy 


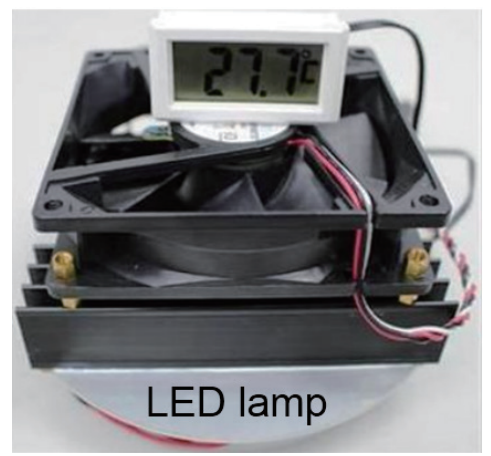

(a)

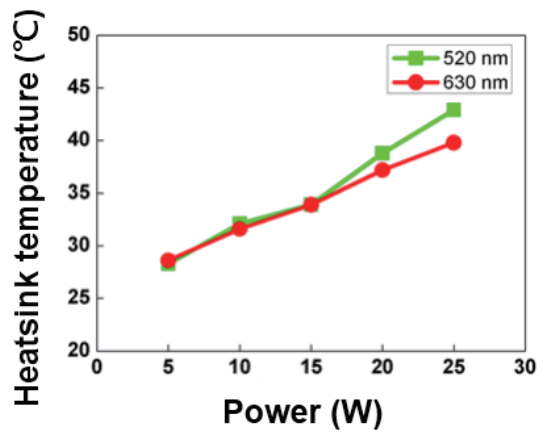

(c)

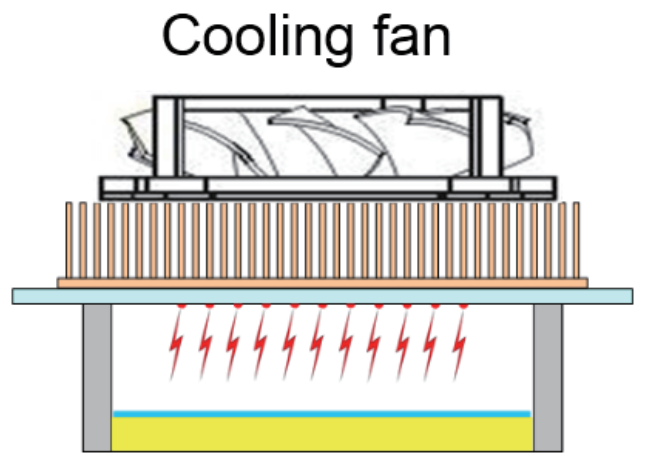

(b)

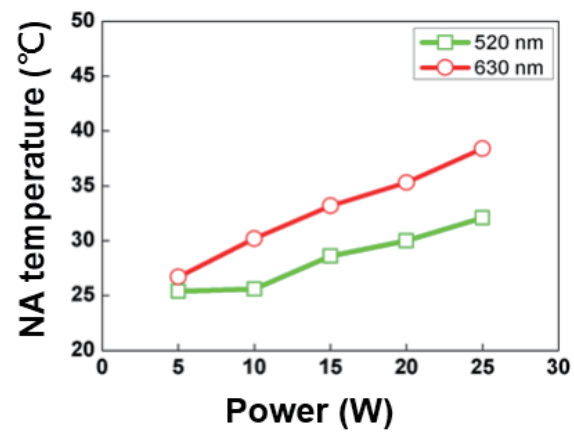

(d)

Fig. 1. (Color online) (a) LED PDI system, (b) schematic of the LED photodynamic system and NA with PS and the bacterial aqueous solution, (c) heatsink temperature of LED lamp, and (d) NA temperature after 5 min irradiation.

light module was composed of 24 high-performance LEDs. The green LED light module (Shwo, 1 W, LM-80 certified, RoHS compliant, SMT type) had a peak irradiance of $525 \mathrm{~nm}\left(I_{40} \%: 500-550\right.$ $\mathrm{nm}$ ) and produced $345 \mathrm{~mW} / \mathrm{cm}^{2}$ over a surface of $60.8 \mathrm{~cm}^{2}$. The red LED light module had a peak irradiance of $630 \mathrm{~nm}\left(I_{40} \%: 610-640 \mathrm{~nm}\right)$ and produced $430 \mathrm{~mW} / \mathrm{cm}^{2}$ over a surface of $60.8 \mathrm{~cm}^{2}$. The conventional white LED light module produced $650 \mathrm{~mW} / \mathrm{cm}^{2}$ over a surface of $60.8 \mathrm{~cm}^{2}$. The spectra and radiant flux were measured using a photometric integrating sphere (SLM-76, Labsphere, North Sutton, USA), as shown in Fig. 2(a). The structure and absorbance of the Er and TBO are shown in Fig. 2(b).

\section{Results and Discussion}

\subsection{PDI efficiency test}

Figures 3(a) and 3(d) show the status of bacterial growth on the NA surface, indicating that nonirradiated $E$. coli and $S$. aureus can survive on the NA, respectively. Figures 3(b) and 3(c) display the results of irradiation of E. coli with $\mathrm{Er}$ and TBO, respectively, indicating that irradiating the samples with Er or TBO reduced the amount of E. coli. Figures 3(e) and 3(f) show that a very small amount of the $S$. aureus bacterial strain remained in the NA that was irradiated with Er or TBO, respectively, indicating a successful reduction in bacterial growth. 


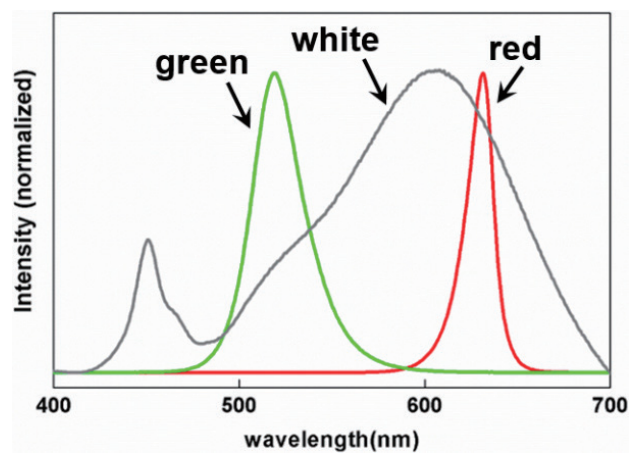

(a)

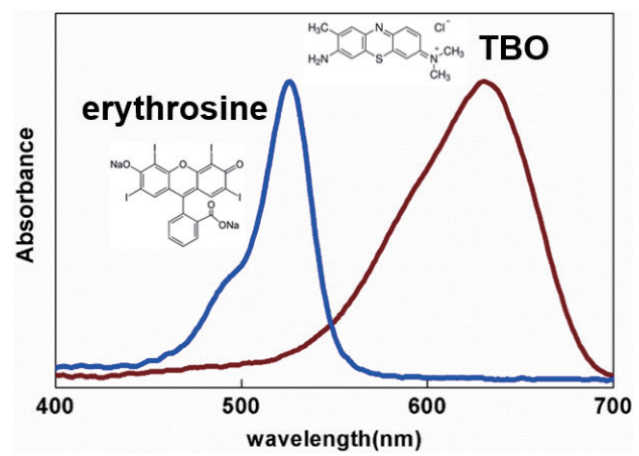

(b)

Fig. 2. (Color online) (a) Spectra of LED lamps, and (b) structures and absorbance spectra of Er and TBO.

A comparison of Figs. 3(b) and 3(e) shows that the PDI effect of the Er PS differed between $E$. coli and $S$. aureus. Although the same irradiation duration and PS concentration were applied to the two bacterial strains, the bacterial growth reduction achieved for the $S$. aureus strain was much higher than that achieved for the E. coli strain after green light irradiation for $60 \mathrm{~s}$. Because $S$. aureus is Gram-positive $[\mathrm{G}(+)]$ and $E$. coli is Gram-negative $[\mathrm{G}(-)]$, the $\mathrm{G}(+)$ bacteria might have been more sensitive to photodynamic sterilization because of their cell wall structure. ${ }^{(34)}$ Because the $\mathrm{G}(+)$ bacterial surface contains peptidoglycan and lipoteichoic acid, the PS can enter the bacteria through the outer wall. The cell walls of $\mathrm{G}(-)$ bacteria have a thin layer of peptidoglycan sandwiched between the inner and outer cell membranes. The outer membrane of $G(-)$ bacteria contains lipopolysaccharide and prions, and can thus block the PS and restrict it from passing into the cell's interior or from combining with proteins on the outer membrane. ${ }^{(35)}$ Therefore, the PDI effect is weaker in the case of $\mathrm{G}(-)$ bacteria.

The SEM images of E. coli and S. aureus without irradiation are shown in Figs. 4(a) and 4(d), respectively; the $30000 \times$ SEM images clearly indicate that the bacterial cells maintained a full and plump shape. In Fig. 4(b), E. coli with Er after green light irradiation, marked with a red circle, exhibited greater changes in shape compared with that in Fig. 4(a). Figure 4(c) shows that most of the $E$. coli cells were unable to maintain their original shape and appearance with TBO after red light irradiation. As displayed in Fig. 4(e), S. aureus with Er after green light irradiation exhibited shrinking and changes in shape. As shown in Fig. 4(f), the surface of $S$. aureus was damaged after irradiation by red LED lamps with TBO. When the cell wall is damaged, the cytoplasm flows out, which inhibits cell division and growth function, leading to cell death. As shown in Figs. 4(b), 4(c), 4(e), and 4(f), under the bacterial PDI effect, the cell walls of both E. coli and S. aureus were damaged, which could be one of the reasons for the reduction in bacterial growth.

When a light-sensitive material is excited by a light source with an appropriate wavelength, an excited singlet or triplet state occurs. The activation cycle of an excited singlet state is extremely short (approximately 1-100 ns) and soon returns to its original state. However, the activation cycle of an excited triplet state is longer (approximately $500 \mathrm{~ns}$ ); depending on whether the PS exhibits charge or energy transfer, it is categorized as a type I or type II reaction. ${ }^{(11)}$ A type I reaction entails electron transfer. After colliding with the surrounding molecules, the PS in an excited triplet state transfers electrons to the molecules, generating free radicals such as hydrogen 


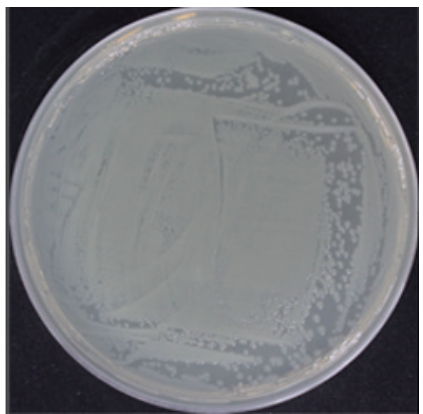

(a)

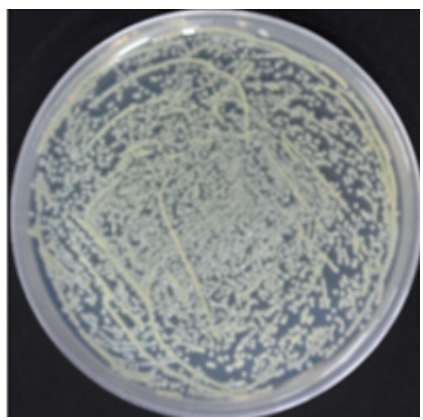

(d)

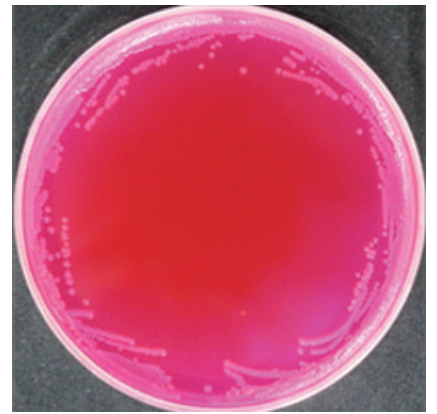

(b)

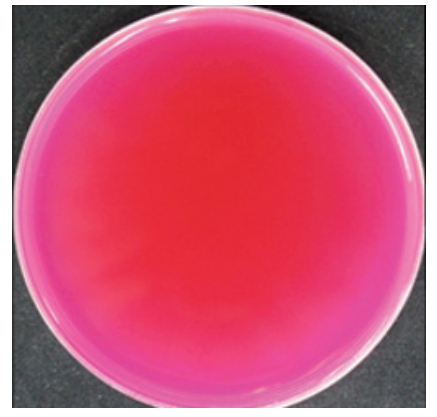

(e)

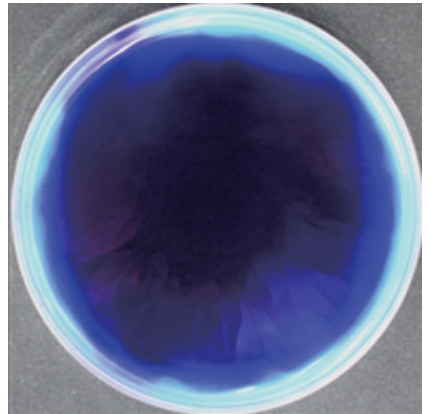

(c)

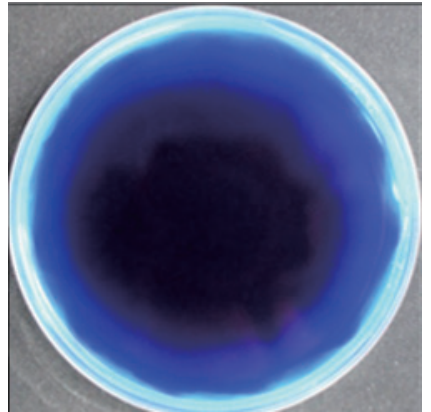

(f)

Fig. 3. Images of (a) E. coli on NA, (b) E. coli with Er irradiated by a green LED lamp for $60 \mathrm{~s}$, (c) E. coli with TBO irradiated by a red LED lamp for $60 \mathrm{~s}$, (d) S. aureus on NA, (e) S. aureus with Er irradiated by a green LED lamp for $60 \mathrm{~s}$, and (f) $S$. aureus with TBO irradiated by a red LED lamp for $60 \mathrm{~s}$.

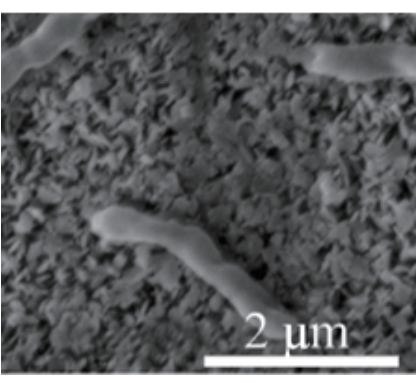

(a)

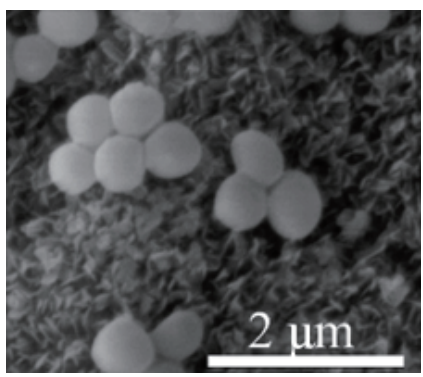

(d)

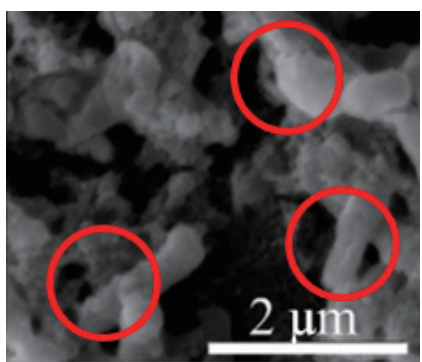

(b)

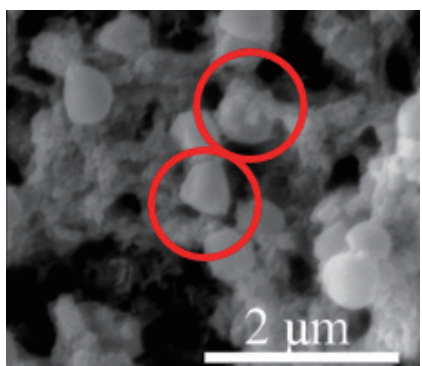

(e)

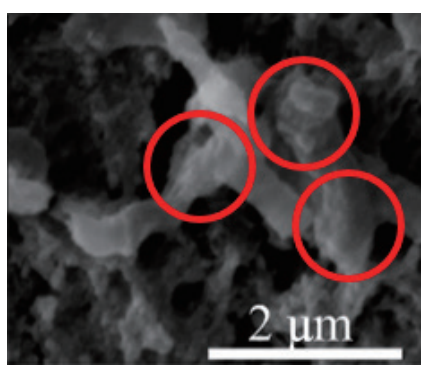

(c)

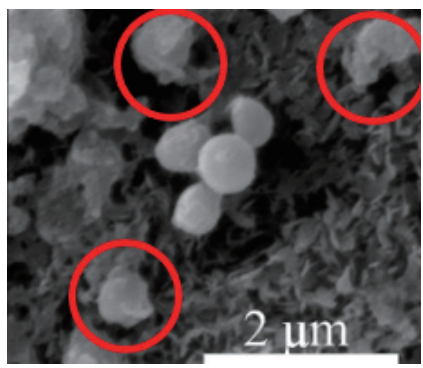

(f)

Fig. 4. SEM images of (a) E. coli without irradiation, (b) E. coli with Er irradiated by a green LED lamp for $60 \mathrm{~s}$, (c) E. coli with TBO irradiated by a red LED lamp for $60 \mathrm{~s}$, (d) S. aureus without irradiation, (e) S. aureus with Er irradiated by a green LED lamp for $60 \mathrm{~s}$, and (f) $S$. aureus with TBO irradiated by a red LED lamp for $60 \mathrm{~s}$. 
peroxides and hydroxyl radicals. These molecules and free radicals can pass electrons to the surrounding ground-state oxygen molecules, generating superoxide radicals and ROS, which damage cells. A type II reaction also entails energy transfer. The PS in an excited triplet state transfers energy directly to the surrounding ground-state oxygen molecules, forming excited ${ }^{1} \mathrm{O}_{2}$, which is unstable and can severely damage biomolecules; cell proteins, nucleic acid, lipids, and membranes are the targets.

After receiving light energy, the PS in PDI converts it into oxygen molecules. Because of the transfer of electrons, superoxide radicals $\left(\mathrm{H}_{2} \mathrm{O}_{2}\right)$, hydroxyl radicals $(\mathrm{OH})$, and superoxide anions $\left(\mathrm{O}_{2}\right)$ are formed, damaging the cell surface; this is called a type I reaction. These substances are highly active and can oxidize phospholipids when they come into contact with bacterial cell walls or membranes, severely damaging the cell membranes, leading to an increase in ion permeability or a loss of membrane fluidity, finally resulting in bacterial death. ${ }^{(36)}$ In the SEM images shown in Fig. 4, the cell walls of both E. coli and S. aureus were severely damaged after irradiation; this could have been caused by the type I reaction.

PDI affects bacteria differently depending on the part of the bacteria to which it is applied. For example, when it is applied to the cell wall and membrane, it can oxidize phospholipids, severely damaging the integrity of the cell membrane; the damage can also spread to cell membrane enzymes, such as respiratory-chain-related enzymes, and inhibit respiration. ${ }^{(37)}$ When PDI is applied to nucleic acid, ${ }^{1} \mathrm{O}_{2}$ may attack guanine bases in the DNA, forming 8-oxohuanine or causing DNA strand breakage. ${ }^{(38)}$ However, in a PDI experiment that used rose bengal as a PS, Ref. 34 indicated that the external layer of the bacteria, rather than DNA, was the primary target; DNA was targeted at a later stage. ${ }^{(39)}$ In a PDI experiment that used hematoporphyrin as a PS, Ref. 35 showed that PDI on methicillin-resistant $S$. aureus did not affect cell proteins; membrane proteins on the surface first exhibited a crosslink phenomenon, and DNA damage appeared only after long-term irradiation, indicating that the hematoporphyrin action occurred on the outside of the cell and that membrane proteins were the primary target; DNA was targeted subsequently. ${ }^{(40,41)}$ This is consistent with the damage mechanism in our study, which is displayed in the SEM image of Fig. 4, indicating the type I reaction damage mechanism.

Figure 5 shows the schematics of the PDI reactions that were observed in this experiment. Figure 5(a) shows the mixing and dropping of $100 \mu \mathrm{L}$ of a bacterial and PS mixture on the aluminum substrate; the painted aluminum substrate was placed in the dark for $10 \mathrm{~min}$. At this point, no irradiation was applied and most of the bacteria were still alive. The observation of the bacterial surface by SEM showed that it remained full of bacteria. Figure 5(b) displays the PDI reaction after irradiation. After absorbing light energy, the PS transferred the energy to oxygen and water, producing ROS such as hydrogen peroxides, hydroxyl radicals, and superoxide radicals. It reacted easily with bacteria and eroded the cell walls. In addition to reacting with the cell membrane, ${ }^{1} \mathrm{O}_{2}$ exerted a greater effect on cell proteins, nucleic acids, and lipids. After reacting with bacteria, this highly oxidized species easily caused cell damage or cell death. Figure 5(c) depicts the gradual death of bacteria under the effect of PDI. As shown in Fig. 5(d), the dead bacteria were dehydrated and dried; observing their surfaces revealed damage on the E. coli and $S$. aureus surfaces, indicating the severe disintegration of bacterial cell walls. Additional experiments are required to obtain data on bacterial death rates, as shown in Table 1, for further evaluation of PDI efficiency.

The results of the quantitative study of the PDI effect on E. coli and $S$. aureus are shown in Table 1. The white light used here was a $25 \mathrm{~W}$ conventional LED lamp. The bacterial death rate 


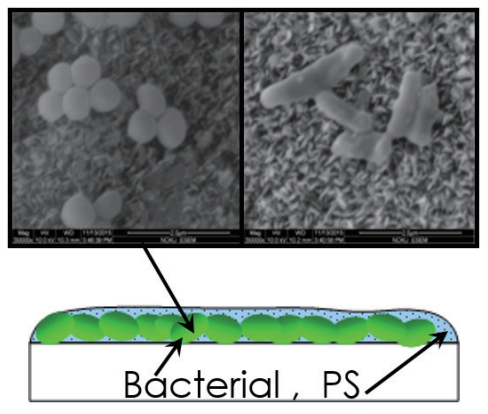

(a)

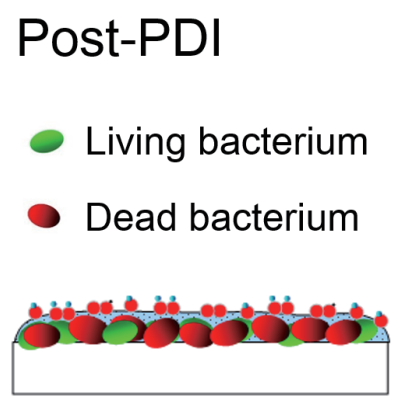

(c)

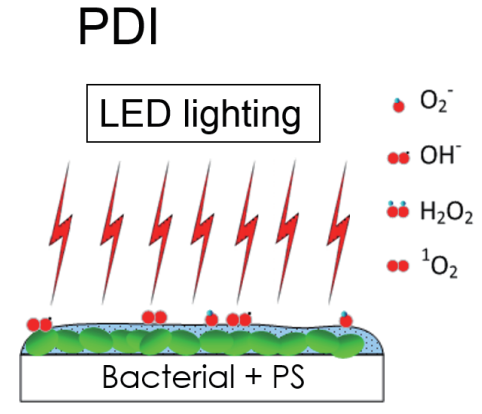

(b)

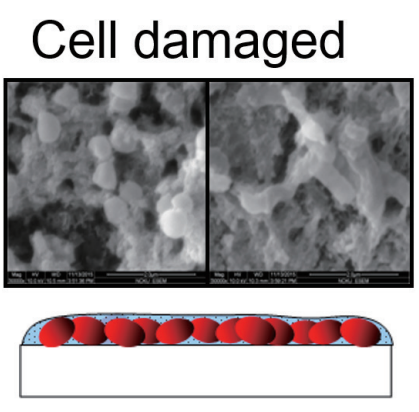

(d)

Fig. 5. (Color online) Steps of PDI reaction: (a) as-prepared sample, (b) PDI reaction, (c) post-PDI, and (d) cell damage.

Table 1

Results of PDI efficiency evaluation.

\begin{tabular}{lcc}
\hline Inactivation condition & Residue colonies & Bacterial death rate $(\%)$ \\
\hline E. coli + Er + green LED & $4.00 \times 10^{6}$ & 25 \\
E. coli + TBO + red LED & $3.97 \times 10^{6}$ & 26 \\
S. aureus + Er + green LED & $3.97 \times 10^{6}$ & 30 \\
S. aureus + TBO + red LED & $3.90 \times 10^{6}$ & 31 \\
E. coli + Er + white LED & $5.07 \times 10^{6}$ & 5 \\
E. coli + TBO + white LED & $4.93 \times 10^{6}$ & 8 \\
S. aureus + Er + white LED & $5.13 \times 10^{6}$ & 9 \\
S. aureus + TBO + white LED & $5.17 \times 10^{6}$ & 9 \\
\hline
\end{tabular}

indicated that E. coli or S. aureus was effective for PDI even with a small lamp power (25 W) and a short illumination time $(60 \mathrm{~s}) .{ }^{(42,43)}$ However, for the purpose of daily life bacterial inactivation, we must conduct more studies to optimize the parameters of the LED lamp, such as lamp power, wavelength, and illumination time.

\section{Conclusions}

Studies have confirmed the positive effect of PDI on $S$. aureus and E. coli growth reduction in the ambient environment using Er and TBO as well as LED light sources. We revealed a decrease 
in the in vitro growth of $S$. aureus and E. coli through a simple PDI technique, with the possibility of using conventional and decorative illuminations to reduce bacterial growth in the environment. Er (as the PS) and LED lamps (as the light source) can be easily obtained, and thus, the PDI effect can be used in our daily life without any additional expense.

\section{Acknowledgments}

The authors gratefully acknowledge the financial support for this project from the Ministry of Science and Technology in Taiwan (MOST 105-2221-E-006-069 and MOST 106-2221-E-006-092MY3). The authors also thank the Center for Micro/Nano Science and Technology and Instrument Center, National Cheng Kung University, and Everlight Electronics for technical support.

\section{References}

1 S. C. Shi: Materials 9 (2016) 856.

2 S. C. Shi and F. I. Lu: Materials 9 (2016) 338.

3 S. C. Shi and C. C. Su: Materials 9 (2016) 612.

4 S. C. Shi, J.-Y. Wu, T.-F. Huang, and Y. Q. Peng: Surf. Coat. Technol. 303 (2016) 250.

5 S. C. Shi and T. F. Huang: Materials 10 (2017) 91.

6 B. L. Ahn, J. W. Park, S. Yoo, J. Kim, H. Jeong, S.-B. Leigh, and C. Y. Jang: Energies 8 (2015) 8736.

7 B. L. Ahn, J. W. Park, S. Yoo, J. Kim, S. B. Leigh, and C. Y. Jang: Energies 8 (2015) 6658.

8 S. R. Lucena, N. Salazar, T. Gracia-Cazana, A. Zamarron, S. Gonzalez, A. Juarranz, and Y. Gilaberte: Int. J. Mol. Sci. 16 (2015) 25912.

9 M. Kimura, K. Miyajima, M. Kojika, T. Kono, and H. Kato: Int. J. Mol. Sci. 16 (2015) 25466.

10 M. Kim, H. Y. Jung, and H. J. Park: Int. J. Mol. Sci. 16 (2015) 23259.

11 M. Wainwright: J. Antimicrob. Chemother. 42 (1998) 13.

12 M. R. Hamblin, D. A. O’Donnell, N. Murthy, C. H. Contag, and T. Hasan: Photochem. Photobiol. 75 (2002) 51.

13 X. Shang, W. Li, Y. Feng, X. Li, and X. Xu: Appl. Sci. 5 (2015) 910.

14 H. Cornell, T. Nguyen, G. Nicoletti, N. Jackson, and H. Hügel: Appl. Sci. 4 (2014) 380.

15 K. Lo, H. Cornell, G. Nicoletti, N. Jackson, and H. Hügel: Appl. Sci. 2 (2012) 114.

16 K. Winkler, C. Simon, M. Finke, K. Bleses, M. Birke, N. Szentmáry, D. Hüttenberger, T. Eppig, T. Stachon, and A. Langenbucher: J. Photochem. Photobiol., B 162 (2016) 340.

17 A. Kumar, V. Ghate, M. Kim, W. Zhou, G. Khoo, and H. Yuk: J. Appl. Microbiol. 120 (2016) 49.

18 Y. Zhang, K. Zheng, Z. Chen, J. Chen, P. Hu, L. Cai, Z. Iqbal, and M. Huang: Appl. Microbiol. Biotechnol. 101 (2017) 4691.

19 M. A. Paschoal, M. Lin, L. Santos-Pinto, and S. Duarte: Lasers Med. Sci. 30 (2013) 885.

20 Y. Taniguchi, A. Aoki, K. Mizutani, Y. Takeuchi, S. Ichinose, A. A. Takasaki, F. Schwarz, and Y. Izumi: Lasers Med. Sci. 28 (2013) 1057.

21 J. R. Silva, G. Cardoso, R. R. Maciel, and N. C. de Souza: Lasers Med. Sci. 30 (2015) 469.

22 A. Aoki, K. Mizutani, F. Schwarz, A. Sculean, R. A. Yukna, A. A. Takasaki, G. E. Romanos, Y. Taniguchi, K. M. Sasaki, and J. L. Zeredo: Periodontology 200068 (2015) 217.

23 J. B. Gillespie, M. Maclean, M. J. Given, M. P. Wilson, M. D. Judd, I. V. Timoshkin, and S. J. MacGregor: Photomed. Laser Surg. 35 (2017) 150.

24 S. D'Ercole, G. Spoto, P. Trentini, D. Tripodi, and M. Petrini: J. Photochem. Photobiol., B 160 (2016) 172.

25 C. C. C. Quishida, E. G. Mima, J. H. Jorge, C. E. Vergani, V. S. Bagnato, and A. C. Pavarina: Lasers Med. Sci. 31 (2016) 997.

26 D. N. Ghista and R. Roaf: Orthopaedic Mechanics: Procedures and Devices (Academic Press Inc., London, 1981).

27 M. R. Hamblin: Curr. Opin. Microbiol. 33 (2016) 67.

28 T. Bornhütter, J. Pohl, C. Fischer, I. Saltsman, A. Mahammed, Z. Gross, and B. Röder: Molecules 21 (2016) 485. 
29 A. H. Alghamdi, H. M. Alshammery, M. A. Abulhasan, and A. F. Alghamdi: Arabian J. Chem. Env. Res. 1 (2015) 1.

30 Y.-H. Lee, H.-W. Park, J.-H. Lee, H.-W. Seo, and S.-Y. Lee: Int. J. Oral Sci. 4 (2013) 196.

31 C. Chui, A. Aoki, Y. Takeuchi, Y. Sasaki, K. Hiratsuka, Y. Abiko, and Y. Izumi: J. Periodontal Res. 48 (2013) 696.

32 H. H. Jajarm, F. Falaki, M. Sanatkhani, M. Ahmadzadeh, F. Ahrari, and H. Shafaee: Lasers Med. Sci. 30 (2015) 1475.

33 G. Sridharan and A. A. Shankar: J. Oral Maxillofacial Pathol. 16 (2012) 251.

34 Z. Malik, H. Ladan, and Y. Nitzan: J. Photochem. Photobiol., B 14 (1992) 262.

35 A. Minnock, D. I. Vernon, J. Schofield, J. Griffiths, J. H. Parish, and S. B. Brown: Antimicrob. Agents Chemother. 44 (2000) 522.

36 W. Korytowski, G. J. Bachowski, and A. W. Girotti: Photochem. Photobiol. 56 (1992) 1.

37 A. W. Girotti: Photochem. Photobiol. 51 (1990) 497.

38 Y. Iwamoto, T. Itoyama, K. Yasuda, T. Morita, T. Shimizu, T. Masuzawa, and Y. Yanagihara: Biol. Pharm. Bull. 16 (1993) 1244.

39 M. Schäfer, C. Schmitz, R. Facius, G. Horneck, B. Milow, K. H. Funken, and J. Ortner: Photochem. Photobiol. 71 (2000) 514.

40 G. Bertoloni, F. M. Lauro, G. Cortella, and M. Merchat: Biochim. Biophys. Acta, Gen. Subj. 1475 (2000) 169.

41 K. R. Kasimova, M. Sadasivam, G. Landi, T. Sarna, and M. R. Hamblin: Photochem. Photobiol. Sci. 13 (2014) 1541.

42 N. N. Yassunaka, C. F. Freitas, B. R. Rabello, P. R. Santos, W. Caetano, N. Hioka, T. U. Nakamura, B. A. Abreu Filho, and J. M. Graton Mikcha: Curr. Microbiol. 71 (2015) 243.

43 M. Sharma, L. Visai, F. Bragheri, I. Cristiani, P. K. Gupta, and P. Speziale: Antimicrob. Agents Chemother. $52(2008) 299$.

\section{About the Authors}

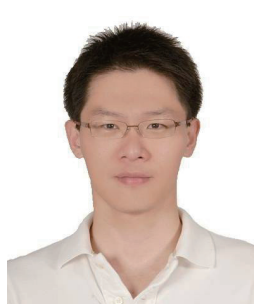

Shih-Chen Shi received his B.S. and M.S. degrees from National Cheng Kung University, Taiwan, in 1999 and 2001, respectively, and his Ph.D. degree from National Chiao Tung University, Taiwan, in 2005. From 2007 to 2012, he was the head of the R\&D department of Everlight Electronic Co., Ltd., Taiwan. Since 2014, he has been an assistant professor at National Cheng Kung University. His research interests are in nanomaterials, tribology, LED application, and sustainable materials.

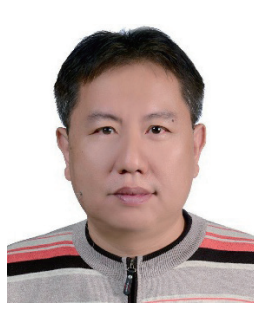

Wen-Ke Huang received his B.S. degree from National Changhua University of Education, and M.S. degree from National Yunlin University of Science and Technology. Since 1993, he has been a full-time teacher at the National Cishan Agricultural \& Industrial Vocational Senior High School. His research interests are in nanomaterials and photodynamic therapy. 